\title{
What priority pollutants occur in stormwater and wastewater?
}

\author{
S. Zgheib ${ }^{1}$, R. Moilleron ${ }^{2}$ \& G. Chebbo ${ }^{1,3}$ \\ ${ }^{1}$ Université Paris-Est, Cereve, UMR-MA102 Ecole des Ponts ParisTech, \\ AgroParisTech, France \\ ${ }^{2}$ Université Paris-Est, Cereve, \\ UMR-MA102 Université Paris-Est Créteil Val de Marne, \\ AgroParisTech, France \\ ${ }^{3}$ Faculté de Génie, Université Libanaise, Lebanon
}

\begin{abstract}
After the implementation of the Water Framework Directive (WFD), there is an increasing need to monitor pollutant concentrations entering surfaces waters. This concerns all kinds of effluents, as well as urban waters (i.e., wastewater and stormwater). This study provides the first database on the occurrence of 88 individual substances in urban water and highlights direct discharges of these substances to the aquatic environment. Indeed, these hazardous pollutants, listed or not in the WFD, could be released without any treatment to watercourses during a storm.
\end{abstract}

Keywords: dissolved phase, particulate phase, priority pollutants, occurrence, wastewater, stormwater, urban catchments, water framework directive.

\section{Introduction}

Assessing concentrations of contaminants in domestic and industrial effluents has become an integral part of risk assessment and environmental regulation. Within this diverse research area there have been many works in the past on metals (Garnaud [1] and Gromaire-Mertz et al. [2]) and persistent organic chemicals, such as PAH (Gasperi et al. [3], Rocher et al. [4] and Grynkiewicz et al. [5]) and PCB (Chevreuil et al. [6]). More recently (Rule et al. [7, 8]), interest has been shown in priority pollutants of the Water Framework Directive $(2000 / 60 / \mathrm{CE})$, whose main objective is to achieve a "good status" for all the 
water bodies. The WFD requires Member States to gain a better understanding of priority substances entering surfaces waters. In fact, water bodies are a major recipient of an extensive array of contaminants produced by human activities. The latter can be discharged into watercourses after incomplete removal by wastewater treatment plants during dry and wet weather periods, by combined sewer overflows and by storm sewers after runoff on impervious urban surfaces.

In addition, Zgheib et al. [9] have noticed that the WFD list does not take into account some pollutants specific to urban areas. So, they extended the list of priority pollutants and defined 88 of them to ensure a good coverage of urban activities. Moreover, they have advised, as a general rule for monitoring water quality, to consider the analysis of contaminants on both the dissolved (D) and the particulate phases. They developed a monitoring or screening methodology taking into account all the precautions from sampling to analysis. All the analyses were performed by a certified French laboratory (Zgheib et al. [9]). This paper provides qualitative results on the occurrence of the 88 priority pollutants: (i) for three separate storm sewer systems with different land use patterns; (ii) for two domestic sewer systems very contrasted in terms of population density and land use features during dry weather periods.

\section{Methodology}

\subsection{Experimental sites, sampling and analytical procedures}

Five sites were investigated in this study to collect wastewater and stormwater as previously described by Zgheib et al. [9] and Zgheib [10]. Three sites, drained by separate storm sewer systems, were chosen to collect the stormwater samples. These sites differ by their land use pattern; there was a residential area in the suburb of Paris, namely Sucy-en-Brie $\left(2.15 \mathrm{~km}^{2}\right.$, with an impervious surface coefficient (ISC) of 0.25), and two urban areas, one in Paris centre, ZAC Paris Rive Gauche $\left(0.64 \mathrm{~km}^{2}\right.$, ICS 0.80$)$ and another in the suburb of Paris, Noisy-leGrand $\left(2.30 \mathrm{~km}^{2}\right.$, ICS 0.65$)$. The two remaining sites differ both in their sewer systems and their surface areas, and were chosen from which to collect wastewater during dry weather periods. Clichy was drained by a combined sewer system (120 km² with an impervious surface coefficient (ISC) of 0.50) and Sucyen-Brie by a separate sewer system $\left(2.15 \mathrm{~km}^{2}\right.$, with an impervious surface coefficient (ISC) of 0.25).

Ordinary water quality parameters, organic and mineral pollutants were analysed on each sample. For this reason, two different refrigerated automatic water samplers $\left(+4^{\circ} \mathrm{C}\right)$ were used to preserve sample integrity. Water samples were collected at the outlet of each watershed. The automatic samplers were programmed to provide a mean rain event sample for stormwater and a mean day sample for wastewater. They allowed collecting 12 x 1 litre samples. They were equipped with two types of containers to avoid any contamination. Hence, for organic pollutants, samples were collected in Pyrex amber glass bottles with Teflon sampling tubes, whereas for mineral pollutants and ordinary water quality parameters, samples were collected in polyethylene (PE) bottles with PVC tube. 
Once the whole water samples were fetched, they were then filtered with a succession of 90-mm pre-combusted glass filters from 2.7 $\mu \mathrm{m}$ (GF/D, Whatman) to $0.7 \mu \mathrm{m}(\mathrm{GF} / \mathrm{F}$, Whatman) in a glass filtration unit. Analyses were carried out on both the dissolved and the particulate phases in accordance with French (AFNOR) or international (ISO) standard methods by a certified laboratory.

\subsection{Occurrence calculation approach}

The results were expressed in $\mathrm{mg} / \mathrm{L}$ for the dissolved phase (D) and the whole water sample or total phase (T), while they were expressed as $\mathrm{mg} / \mathrm{kg}$.dw for the particulate phase. Any substance was considered as present in a given sample, when its concentration was above the limit of detection (LOD) in, at least, one of the phases $(\mathrm{D}, \mathrm{P})$ or the whole water sample $(\mathrm{T})$ for volatile organic compounds (VOCs). On the contrary, when the concentrations were below LOD for all phases, the substance was marked as absent in the given sample. This approach was applied to evaluate the occurrence of all pollutants in a given matrix, e.g., stormwater (SW) and wastewater (WW). The occurrence for all the contaminants was estimated for each matrix, SW or WW, and for each sampling location sample. The occurrence $_{i j}$ was defined as the percentage of presence for a substance (i) in a matrix or a site (j) as follows:

$$
\text { occurence }_{i j}(\%)=\frac{s_{i}}{n_{j}} \times 100
$$

where $s_{i}$ is the number of times when the substance (i) was present in a sample for a matrix or a site $(\mathrm{j})$ and $n_{j}$ was the number of samples.

Similarly, the percentage of substances detected in the different phases (e.g., P, D or T) of a sample was:

$$
\text { substances detected }(\%)=\frac{\mathrm{s}_{\text {det ected }}}{\mathrm{N}} \times 100
$$

where $s_{\text {detected }}$ is the number of substances detected for a site or matrix; $N$ is the total number of investigated substances. This number $(\mathrm{N})$ depends on the phase under investigation: $\mathrm{N}=73$ for both the dissolved and the particulate phases (D $+\mathrm{P}), \mathrm{N}=15$ for the whole water sample ( $\mathrm{T}$ ) and, finally, $\mathrm{N}=88$ for the total sample (i.e., $\mathrm{D}+\mathrm{P}+\mathrm{T}$ ). Moreover, the substances were divided into three groups: the priority dangerous substances ( $\mathrm{sdp}, \mathrm{n}=26)$, priority substances $(\mathrm{sp}, \mathrm{n}$ $=17$ ), with respect to WFD requirements, and the other substances more specific to urban pollution (others, $\mathrm{n}=45$ ).

\section{Results and discussion}

\subsection{Occurrence of priority pollutants in stormwater}

Thirteen samples of stormwater were collected from the three sites (Sucy-enBrie, Noisy-le-Grand and ZAC Paris Rive Gauche). The screening revealed that stormwater samples contained 55 different individual substances or $62.5 \%$ of the 
substances investigated. An overview of both the type and the number of substances found in stormwater is summarized in table 1 .

Among these substances, $64 \%$ belongs to the group of substances more specific to urban pollution. $36 \%$ of the substances derived from the WFD: $22 \%$ were priority substances and $14 \%$ were priority dangerous substances. Our results showed that only 5 VOCs were identified in stormwater and 50 organic substances or metals have been observed in at least one of the dissolved or particulate phases $(\mathrm{D}+\mathrm{P})$, while 33 substances have never been quantified. Overall, the total number of substances in stormwater whatever the site was comparable. In fact, the most frequently detected substances belong mainly to the following chemical families: metals, PAHs, PCBs, alkylphenols, organotins, phthalates and pesticides. Some chlorophenols and VOCs were less observed. No chloroalkane or PBDE and chlorobenzene were detected in stormwater (fig. 1).

Focussing on specific compounds to each site (fig. 1), one noted that the sites of ZAC Paris Rive Gauche and Noisy-le-Grand, representative of dense urban areas, were distinguished by the presence of certain VOCs (25\% of samples), including methylene chloride (for $50 \%$ of samples), whereas these compounds

Table 1: $\quad$ Number of substances in SW and WW per sites, phases and types.

\begin{tabular}{cccccccccc}
\hline & $\mathbf{N}_{\text {sample }}$ & $\mathbf{D}$ & $\mathbf{P}$ & $\mathbf{D}+\mathbf{P}$ & $\mathbf{T}$ & $\mathbf{S p}$ & $\mathbf{s d p}$ & others & D+P+T \\
\hline $\mathbf{N}_{\text {substances }}$ & & 73 & 73 & 73 & 15 & 26 & 17 & 45 & 88 \\
\hline ZAC Paris Rive & 4 & 23 & 36 & 41 & 5 & 10 & 6 & 30 & 46 \\
Gauche & 4 & 22 & 38 & 44 & 1 & 10 & 8 & 27 & 45 \\
Noisy-le-Grand & 5 & 30 & 39 & 45 & 0 & 11 & 7 & 27 & 45 \\
Sucy-en-Brie & $\mathbf{1 3}$ & $\mathbf{3 4}$ & $\mathbf{4 2}$ & $\mathbf{5 0}$ & $\mathbf{5}$ & $\mathbf{1 2}$ & $\mathbf{8}$ & $\mathbf{3 5}$ & $\mathbf{5 5}$ \\
\hline SW synthesis & 4 & 29 & 34 & 47 & 7 & 12 & 7 & 35 & 54 \\
\hline Clichy - WW & 4 & 21 & 30 & 36 & 5 & 10 & 7 & 24 & 41 \\
Sucy-en-Brie-WW & & & & & & & & &
\end{tabular}

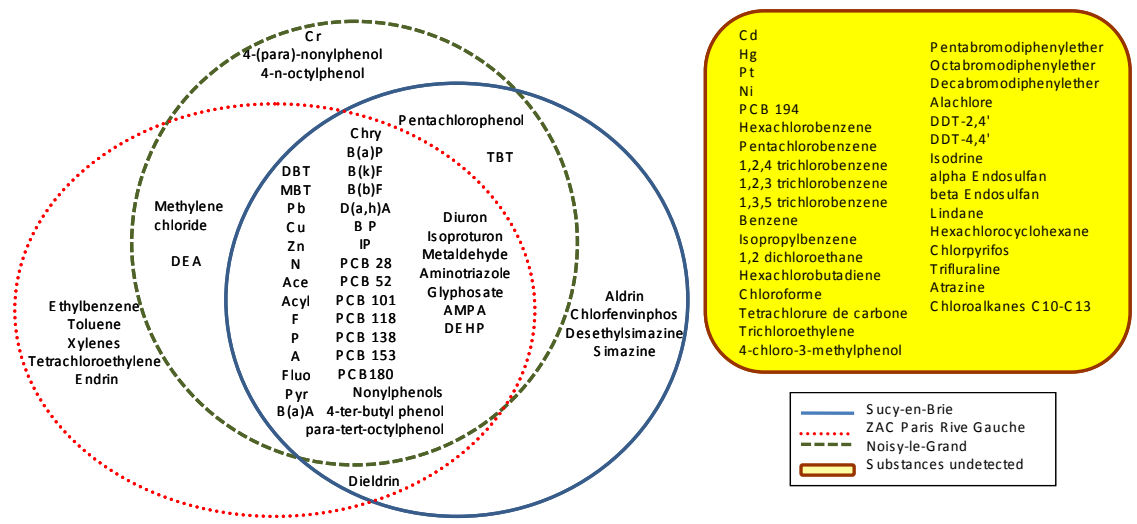

Figure 1: Recapitulative scheme on the presence of the 88 substances in stormwater associated with the land use pattern. 
were absent in the samples from the residential area of Sucy-en-Brie. This latter was characterized by the presence of a large number of pesticides (aldrin, simazine, desethylsimazine, and chlorfenvinphos). Finally, Cr, 4-(para)nonylphenol and 4-n-octylphenol were observed only on samples from Noisy-leGrand. However, 33 substances were never detected whatever the site. Their concentrations were always below LOD. This was the case of some metals $(\mathrm{Cd}$, $\mathrm{Hg}, \mathrm{Pt}, \mathrm{Ni}$ ), PCB 194, chlorobenzenes (tri-, penta- and hexachlorobenzene), most VOCs (benzene, chloroform, trichlorethylene, isopropylbenzene, 1,2dichloroethane, hexachlorobutadiene, carbon tetrachloride, trichlorethylene), 4chloro-3-methylphenol, PBDEs, some pesticides (alachlor, 2,4'-DDT, 4,4'-DDT, isodrin, endosulfan, hexachlorocyclohexan, chlorpyrifos, trifluralin, atrazine, endosulfan, lindane,) and C10-C13 chloroalkanes. The absence of VOCs might be related to a bias in the sampling procedure, not suitable for the analysis of these substances. Indeed, samples were collected only at the end of the storm, increasing the risk of losses. Moreover, COVs are known as having a high volatility, which participate in their transfer to the atmosphere, and shortening of their residence time in samples. To improve the analysis of $\mathrm{COV}$, a punctual sampling seemed to be more appropriate. Furthermore, many reasons can explain the non-detection of certain pesticides. However, the main reason would be the stop of their uses. Most of these pesticides are now banned from use in France. To confirm this, more pesticide monitoring would have been necessary during their application periods (in spring and fall) at all sites. Finally, some LODs were too high to enable the quantification of some substances (i.e., $\mathrm{Cd}, \mathrm{Ni}, \mathrm{PBDE}$ ). This remains one of the main problems working with certified laboratories. Their LOD are somehow quite high for some contaminants, when they are compared to those generally achieved by research centres. Nevertheless, since in many countries, regulation lays down to sewer network managers to work with those organisms, they must face such constraints. The occurrence for every site is illustrated in fig. 2. Stormwater reveals the following characteristics. PAHs were ubiquitous; the 16 PAHs were systematically quantified in all samples for all sites. DEHP, a priority substance, was also present in all samples. Although the use of PCBs has been progressively restricted in France in 1979, with the prohibition of their use (in inks, adhesives, as additives in some oils...), then in 1987 with the prohibition of the sale, acquisition or marketing of equipment containing PCBs (transformers), all PCB congeners without PCB194 were observed for all sites.

For Noisy-le-Grand and ZAC Paris Rive Gauche, the dense urban areas, three metals, $\mathrm{Cu}, \mathrm{Pb}$ and $\mathrm{Zn}$ were quantified in $100 \%$ of the samples. For Sucy-enBrie, the trend was similar for $\mathrm{Cu}$ and $\mathrm{Zn}$, whereas $\mathrm{Pb}$ was present in a lesser proportion (77\% of cases). Cr, meanwhile, has been detected in only $67 \%$ of Noisy-le-Grand samples. For organotins, only DBT and MBT were common to all sites, but in proportions differing from one site to another: $100 \%$ for both substances at Noisy-le-Grand and ZAC Paris Rive Gauche. For Sucy-en-Brie, DBT was present in $83 \%$ of samples, while MBT was in $33 \%$ of them. TBT, a priority dangerous substance, has been observed on Noisy-le-Grand and Sucyen-Brie in $100 \%$ and $17 \%$ of the samples, respectively. 

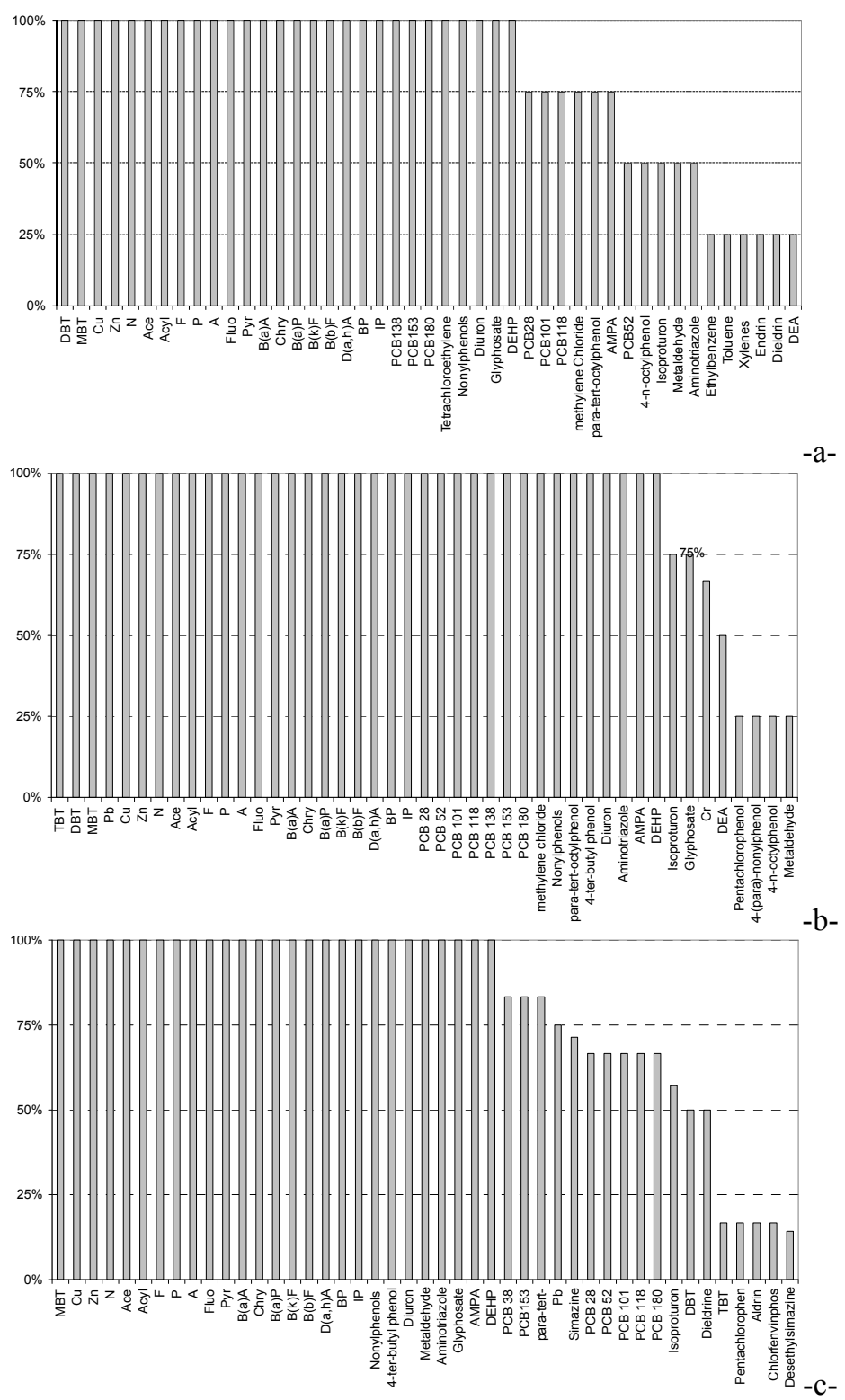

Figure 2: Occurrence of pollutants in stormwater in Paris ZAC Paris Rive Gauche (a); Noisy-le-Grand (b); and Sucy-en-Brie (c). 
Two pesticides, namely isoproturon and diuron, were present respectively in 60 and $100 \%$ of stormwater samples. Moreover, all these samples were also contaminated with 4 other pesticides (metaldehyde, aminotriazole, glyphosate and its main degradation product AMPA). The degradation product of atrazine (a herbicide banned in France since 2003), the desethylatrazine (DEA), was common to both dense urban sites, while dieldrin (banned since 1994) was measured on the ZAC Paris Rive Gauche (25\%) and Sucy-en-Brie (60\%).

Three alkylphenols have been observed in more than $75 \%$ of samples, all sites combined: nonylphenol, para-tert-butylphenol and para-tert-octylphenol. Sucyen-Brie was contaminated by all alkylphenols in more than $25 \%$ of cases. As previously mentioned, VOCs was the group of substances the least observed in stormwater, this seems to be in contradiction with what has been reported for wastewater releases in a previous study by Greaud-Hoveman et al. [11]. COVs were indeed present in $46 \%$ of samples, ranking just behind metals and PAHs Greaud-Hoveman et al. [11]. This underlines their strong domestic and industrial origins. Furthermore, stormwater samples from the dense urban site of the ZAC Paris Rive Gauche contained tetrachlorethylene (100\% of cases). Tetrachloroethylene is mainly used as a solvent in dry cleaning and metal cleaning. It is also used for processing and finishing in the textile industry Rule et al. [8]. Finally, pentachlorophenol was present in $25 \%$ of samples from Noisyle-Grand and Sucy-en-Brie. On the ZAC Paris Rive Gauche site, it was detected in one sample but not quantifiable $(<\mathrm{LOQ})$. Pentachlorophenol is an ingredient of insecticides and fungicides Rule et al. [8]. This contaminant has not been observed in runoff in London, its absence was related to the prohibition of its use according to Rule et al. [8].

\subsection{Occurrence of priority pollutants in wastewater}

During dry weather periods, eight samples of wastewater were collected at the outlet of two different sewer systems (a combined and a separate one), they were analysed for the 88 substances. 54 substances were quantified in the combined sewer and 41 in the separated sewer, $61 \%$ and $47 \%$ of the 88 investigated substances, respectively (table 1). Although both domestic wastewater watersheds are contrasted in terms of land use patterns and type of sewer, many compounds were common in both sites. More precisely, 16 PAHs were observed in $100 \%$ of the samples from both sewer systems (fig. 3). This result is quite different from that previously reported for the analysis of PAHs in wastewater samples from the Parisian combined sewer network, during dry weather periods, by Gasperi et al. [12], where the occurrence for each PAH varied between 0 and $75 \%$. However, analyses were carried out on the whole water sample in that study. This clearly shows that analyses on whole water samples with substantial amount of suspended matter are much less efficient for those substances than if performed on suspended matter itself, using suitable methods for solid phases.

For organotins, both sewer systems, exhibited the same trends, since DBT, TBT and MBT were observed in more than $50 \%$ of the samples. Two metals (Zn and $\mathrm{Cu}$ ) were systematically observed in our samples in good accordance with previous studies from Garnaud [1], Rule et al. [7] and Gasperi et al. [12]. DEHP 
and alkylphenols, such as branched nonylphenol, para-tert-octylphenol and 4-terbutylphenol, were also measured in all the samples. For VOCs, we noted the presence of chloroform in most of the samples along with toluene and xylene. The occurrence of pesticides varies, depending on the compound. However, diuron and AMPA were both present in $100 \%$ and $75 \%$ of cases, respectively. Glyphosate, aminotriazole, 2-4'-DDT, dieldrin, chlorfenvinphos, metaldehyde and DEA have been observed with pentachlorophenol, at least once in a sample. The sole PCB 28 was measured in one sample at Sucy-en-Brie. This contrasted with the samples from combined sewers, where all the PCBs were quantified at
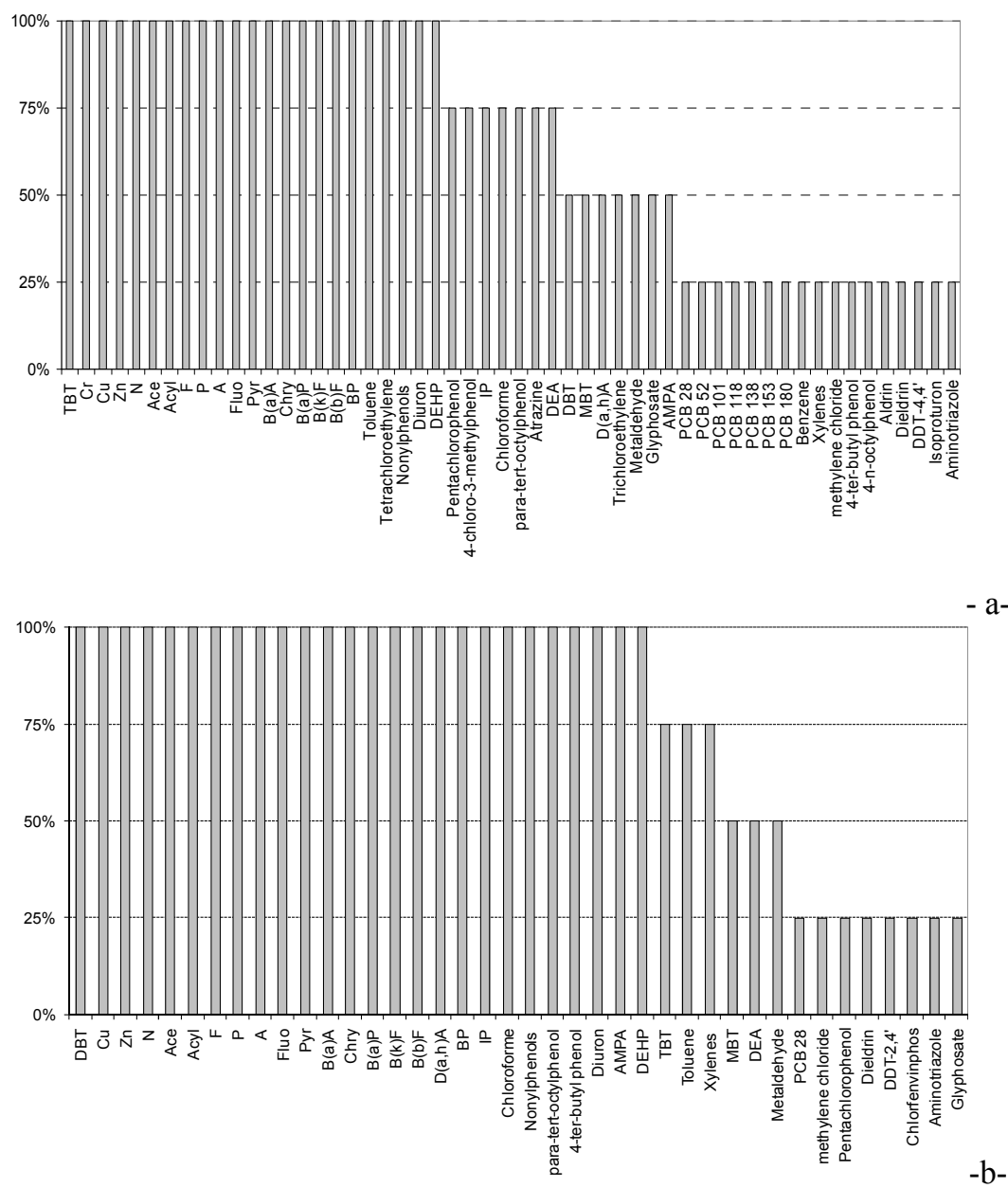

Figure 3: Occurrence of pollutants in wastewater from (a) a combined sewer system at Clichy and (b) from a separate sewer system at Sucy-enBrie. 


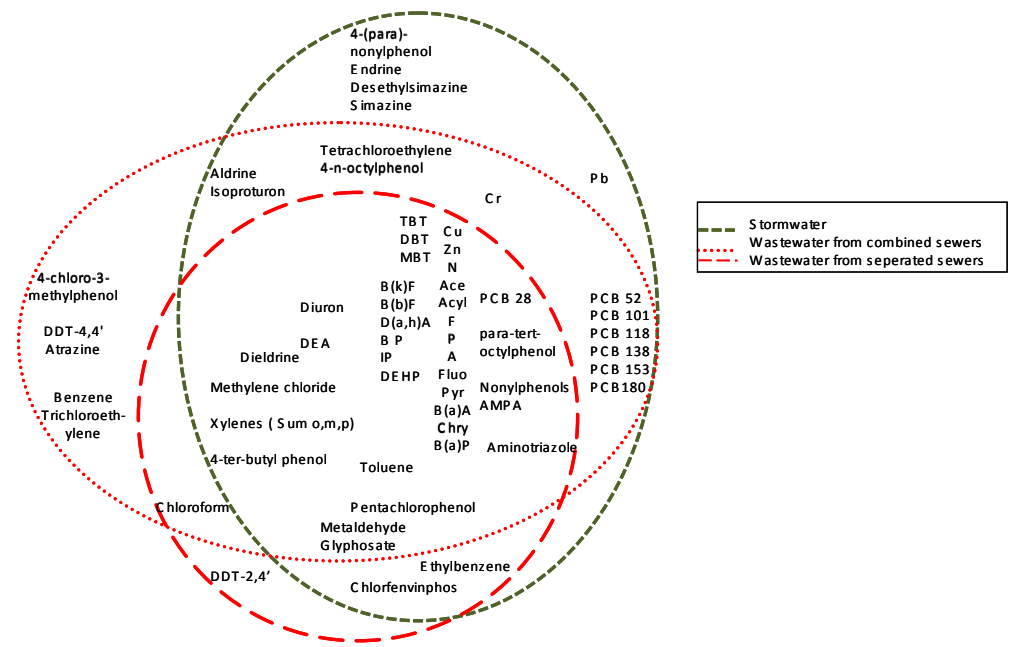

Figure 4: Recapitulative scheme on the presence of the pollutants in stormwater and wastewater.

least once (25-100\%). Besides, the presence of ethylbenzene, 2-4'-DDT and chlorfenvinphos at Sucy-en-Brie can be related to their local use. Finally, some pollutants were never measured in wastewater from both the combined and the separate sewer systems: PCBs (congeners 52, 101, 118, 138, 153), some pesticides and $\mathrm{Cr}$.

\section{Conclusion}

This paper describes the first results in Europe on the occurrence of priority pollutants in urban waters using an original methodology, called "screening". A list of 88 pollutants were analysed on 13 stormwater samples and 8 wastewater samples on both the dissolved and the particulate phases. Results showed that the number of substances in urban water was relatively comparable from one matrix to another (stormwater or wastewater). Although some substances were common to several matrices (28 substances), some other appeared to be more specific to a particular matrix (fig. 4). The wastewater was characterized by a greater number of VOCs and the stormwater by the presence of pesticides. Moreover, the number and the nature of pollutants were relatively comparable from one sample to another for different land use patterns, as observed for storm sewer systems, and for different type of sewer systems, as for wastewater.

\section{Acknowledgements}

The authors gratefully acknowledge the Seine-Normandy Water Agency (AESN), the Interdepartmental Association for Sewage Disposal in Paris 
Conurbation (SIAAP), the Municipality of Paris, the Water and Sewage Disposal Departmental Administrations of Seine Saint Denis (DEA93), the Water and Sewage Disposal Departmental Administration of Val de Marne (DSEA94) and Regional Council of "Ile de France" (CRIF) for their financial support within the framework of the OPUR programme research.

\section{References}

[1] Garnaud, S. Transfert et évolution géochimique de la pollution métallique en bassin versant urbain. Ph.D thesis, Ecole Nationale des Ponts et Chaussées. 396p., 1999.

[2] Gromaire-Mertz, M.C., Garnaud, S., Gonzalez, A., and Chebbo, G., Characterisation of urban runoff pollution in Paris. Water Science and Technology. 39(2), p. 1-8, 1999.

[3] Gasperi J., Rocher V., Moilleron R. and Chebbo G., Review on the hydrocarbons fate within combined sewers: case of the "Le Marais" urban catchment (1994-2005). Polycyclic Aromatic Compounds. 27(2), p. 123141, 2007.

[4] Rocher V., Azimi S., Gasperi J., Beuvin L., Muller M., Moilleron R. and Chebbo G., Hydrocarbons and metals in atmospheric deposition and roof runoff in central Paris. Water Air and Soil Pollution. 159(1-4), p. 67-86, 2004.

[5] Grynkiewicz M., Polkowska Z. and Namiesnik J., Determination of polycyclic aromatic hydrocarbons in bulk precipitation and runoff waters in an urban region (Poland). Atmospheric Environment 36(2), p. 361-369, 2002.

[6] Chevreuil M., Garmouma M., Teil M. J. and Chesterikoff A., Occurrence of organochlorines (PCBs, pesticides) and herbicides (triazines, phenylureas) in the atmosphere and in the fallout from urban and rural stations of the Paris area. Science of the Total Environment. 182, p.1-3, 1996.

[7] Rule, K.L., Comber, S.D.W., Ross, D., Thornton, A., Markropoulos, C.K., and Rautiu, R., Survey of priority substances entering thirty English wastewater treatment works. Water and Environment Journal. 20, p. 177 184, 2006.

[8] Rule, K.L., Comber, S.D.W., Ross, D., Thornton, A., Makropoulos, C.K., and Rautiu, R., Sources of priority substances entering an urban wastewater catchment--trace organic chemicals. Chemosphere. 63(4), p. 581-591, 2006.

[9] Zgheib S., Moilleron R. and Chebbo G. Screening of priority pollutants in urban stormwater: innovative methodology. Water Pollution IX 111: p. 235-244, 2008.

[10] Zgheib S. Flux et sources des polluants prioritaires dans les eaux urbaines en lien avec l'usage du territoire. Ph.D thesis, Ecole Nationale des Ponts et Chaussées. 349p., 2009.

[11] Greaud-Hoveman L., Barré H., Houeix N., Lepot B., Lehnhoff C., Schneider M., Aguerre-Charol O. and Morin A., Les substances 
dangereuses pour le milieu aquatique dans les rejets industriels et urbains. Rapport d'étude d'INERIS: 611 p., 2008.

[12] Gasperi J., Garnaud S., Rocher V. and Moilleron R. Priority pollutants in wastewater and combined sewer overflow. Science of the Total Environment 407(1): p. 263-272, 2008. 